\title{
Analisis Simpang Bersinyal Terkoordinasi Pada Ruas Jalan Soekarno-Hatta Ponorogo
}

\author{
Mohammad Fatkhul Amal ${ }^{1)}$ \\ 1) Dinas Perhubungan Kabupaten Ponorogo, Jl. Halim Perdana Kusuma No.12, Tonatan, Kec. Ponorogo, \\ Kabupaten Ponorogo, Jawa Timur 63471. Email: amals.fetz@gmail.com
}

\begin{abstract}
Abstrak
Kinerja ruas jalan dan persimpangan dipengaruhi oleh jumlah kendaraan yang melewatinya dengan kecepatan masing-masing kendaraan tersebut. Semakin padat arus lalu lintas maka kecepatan akan berkurang sehingga kinerja jalan semakin menurun, begitu juga dengan persimpangan akan menurun kinerjanya jika antrian dan tundaannya tinggi. Perlu perencanaan dan pengaturan kinerja ruas jalan maupun persimpangan sehingga dapat mengkoordinasikan masing-masing simpang yang telah diatur dengan APILL (Alat Pemberi Isyarat Lalu Lintas) sehingga dapat berakibat mengurangi permasalahan- permasalahan yang ada pada persimpangan. Jalan SoekanoHatta merupakan salah satu jalan penghubung antara Kota/Kabupaten Madiun dengan Ponorogo, sehingga kelancaran arus lalu lintas pada ruas jalan tersebut sangat penting. Letak ruas jalan itu juga berada dikawasan penting perkotaan Ponorogo. Ada tiga simpang yang menjadi lingkup kajian yaitu simpang Kalimantan, simpang Pasar Legi dan simpang Ngepos yang kesemuanya jalan mayornya adalah jalan Soekarno-Hatta. Kondisi pengaturan simpang pada tiga simpang tersebut menggunakan APILL tidak terkoordinasi mengakibatkan panjangnya antrian dan lama nya tundaan untuk melintas jalan tersebut. Setelah dilakukan perubahan waktu siklus dan kecepatan rencana menjadi $40 \mathrm{~km} / \mathrm{jam}$ maka terjadinya kordinasi antara ketiga simpang tersebut. Kecepatan rencana jalan Soekarno-Hatta untuk terjadinya koordinasi simpang adalah $35 \mathrm{~km} / \mathrm{jam}$ dibawah batas maksimal kecepatan dikawasan perkotaan dan travel time atau waktu perjalanan yang sebelumnya 190 detik (3 menit) menjadi 65 detik..
\end{abstract}

Kata kunci: Kinerja Jalan, Ruas, Simpang Terkoordinasi, Tundaan.

\begin{abstract}
The performance of roads and intersections is influenced by the number of vehicles that pass through it at the speed of each vehicle. The more congested traffic flow, the speed will decrease so that the performance of the road decreases, as well as the intersection will decrease its performance if the queue and delays are high. It is necessary to plan and manage the performance of roads and intersections so that they can coordinate each intersection that has been arranged with APILL (Traffic Signal Giving Tool) so that it can result in reducing the problems that exist at the intersection. Soekarno-Hatta Street is one of the connecting roads between the City / Regency of Madiun and Ponorogo, so that the smooth flow of traffic on these roads is very important. The location of the road is also in the important urban area of Ponorogo. There are three intersections that become the scope of the study, which are the Kalimantan intersection, the Pasar Legi intersection and the Ngepos intersection, all of which major roads are the Soekarno-Hatta road. The condition of crossing arrangements at these three intersections using uncoordinated APILL results in long queues and long delays to cross the road. After changing the cycle time and speed of the plan to $40 \mathrm{~km} / \mathrm{hr}$, coordination occurs between the three intersections. The speed of the Soekarno-Hatta road plan for the intersection coordination is $35 \mathrm{~km} / \mathrm{h}$ under the maximum speed limit in the urban area and travel time or travel time which was previously 190 seconds (3 minutes) to 65 seconds.
\end{abstract}

Keywords: Coordinated Intersections, Delay, Road Performance, Segment.

\section{PENDAhuluan}

Pertumbuhan penduduk yang semakin pesat di wilayah perkotaan berdampak bertambahnya arus lalu lintas pada suatu kota dan semakin padatnya ruas jalan maupun persimpangannya, dalam berlalu lintas pengguna kendaraan akan menggunakan prasarana lalu lintas seperti jalan, persimpangan jalan, trotoar dan lainnya.
Transportasi adalah pergerakan manusia, barang dan informasi dari suatu tempat ke tempat lain dengan aman, nyaman, cepat, murah, dan sesuai dengan lingkungan untuk memenuhi kebutuhan hidup manusia (Budiarto dan Mahmudah, 2007).

Perencanaan transportasi adalah usaha untuk meramalkan dan mengelola evaluasi titik 
keseimbangan sejalan dengan waktu sehingga kesejaheraan sosial dapat dimaksimumkan. Secara umum perencanaan transportasi adalah untuk memastikan bahwa kebutuhan akan pergerakan dalam bentuk pergerakan manusia, barang atau kendaraan dapat ditunjang oleh prasarana transportasi yang harus beroperasi dari bawah kapasitasnya (Tamin, 2008).

Kebutuhan transportasi yang meningkat menimbulkan berbagai masalah transportasi. Salah satunya berkaitan dengan jumlah pergerakan suatu zona. Hal ini membutuhkan suatu perencanaan transportasi yang memberikan suatu model pergerakan yang berfungsi untuk mengatasi permasalahan transportasi baik sekarang maupun masa mendatang. Kinerja ruas jalan dan persimpangan dipengaruhi oleh jumlah kendaraan yang melewatinya dengan kecepatan masing-masing kendaraan tersebut, semakin padat arus lalu lintas maka kecepatanpun akan berkurang sehingga kinerja jalan semakin menurun, begitu juga dengan persimpangan akan menurun kinerjanya jika antrian dan tundaannya tinggi oleh karena itu perlu adanya kajian untuk merencanakan dan mengatur kinerja ruas jalan maupun persimpangan sehingga dapat mengkoordinasikan masing-masing simpang yang telah diatur dengan APILL (Alat Pemberi Isyarat Lalu Lintas) sehingga dapat mengurangi permasalahan - permasalahan yang ada pada persimpangan (Arifin, 2019; Firman, 2016; Sari, 2017).

Persimpangan jalan adalah daerah atau tempat dimana dua atau lebih jalan raya yang berpencar, bergabung, bersilangan dan berpotongan, termasuk fasilitas jalan dan sisi jalan untuk pergerakan lalu lintas pada daerah itu. Fungsi operasional utama dari persimpangan adalah untuk menyediakan perpindahan atau perubahan arah perjalanan, persimpangan merupakan bagian penting dari jalan raya karena sebagian besar dari efisiensi, keamanan, kecepatan, biaya perasional dan kapasitas lalu lintas tergantung pada perencanaan persimpangan. Tundaan yang terjadi pada persimpangan dapat menimbulkan kerugian bagi pengguna jalan (Khafidz et al., 2016; Nurdjanah, 2019). Dengan adanya pengaturan dan pengkoordinasian simpang maka dapat mengurangi panjang antrian dan tundaan yang terjadi (Ikhwan et al., 2014; Paramarto et al., 2014; Zega and Surbakti, 2013).

Penelitian ini dibutuhkan karena beberapa simpang yang berada diruas jalan SoekarnoHatta ini sudah menggunakan APILL dalam pengaturannya oleh Karena itu perlu saling terkoordinasi antar simpang tersebut agar pengguna jalan tidak terkena lampu merah pada setiap simpang ber-APILL tersebut. Penelitian dilakukan dengan mengunakan program APLIKASI Vissim-11 (AG, 2017) untuk mengolah data yang di peroleh dengan mengunakan program Vissim-11 maka penulis bermaksud untuk dapat memperoleh output yang dibutuhkan seperti tundaan dan antrian simpang dan visualisasinya sehingga beberapa simpang bersinyal dapat terkoordinasi serta dapat dijadikan acuan dalam pengambilan kebijakan oleh pemerintah setempat.

Adapun tujuan dari penelitian ini adalah untuk mengetahui antrian dan waktu tundaan persimpangan bersinyal di ruas Jalan Soekarno-Hatta Ponorogo. Penelitain juga dilakukan untuk merencanaan kecepatan dan mengkoordinasikan APILL (Alat Pemberi Isyarat Lalu Lintas) pada ruas Jalan SoekarnoHatta sehingga waktu perjalanan lebih singkat untuk melintasi Jalan Soekarno-Hatta

\section{METODE}

Penelitian ini menggunakan metode deskriptif analitis yaitu melakukan pengumpulan dan penyusunan data awal kemudian menjelaskan dan menganalisis sehingga dapat menghasilkan kesimpulan atas permasalahan yang ada. Permasalahan yang dikaji adalah tidak adanya koordinasi pengaturan APILL pada Simpang 4 Kalimantan, Simpang 4 Pasar Legi dan Simpang 3 Ngepos sehingga antrian pajang, lama waktu tundaan dan waktu perjalanan lama.

\section{Metode penelitian}

Penelitin dilakukan pada beberapa titik jalan yang menghubungkan kendaraan dari arah madiun ke titik perkotaan Kabupaten Ponorogo atau sebaliknya sebagai lokasi penelitian. Terlihat pada gambar 3.1. yaitu letak lokasi penelitian yang menghubungkan Madiun ke Kawasan perkotaan Ponorogo, meliputi :

1. Simpang 4 Kalimantan

2. Simpang 4 Pasar Legi 
3. Simpang 3 Ngepos

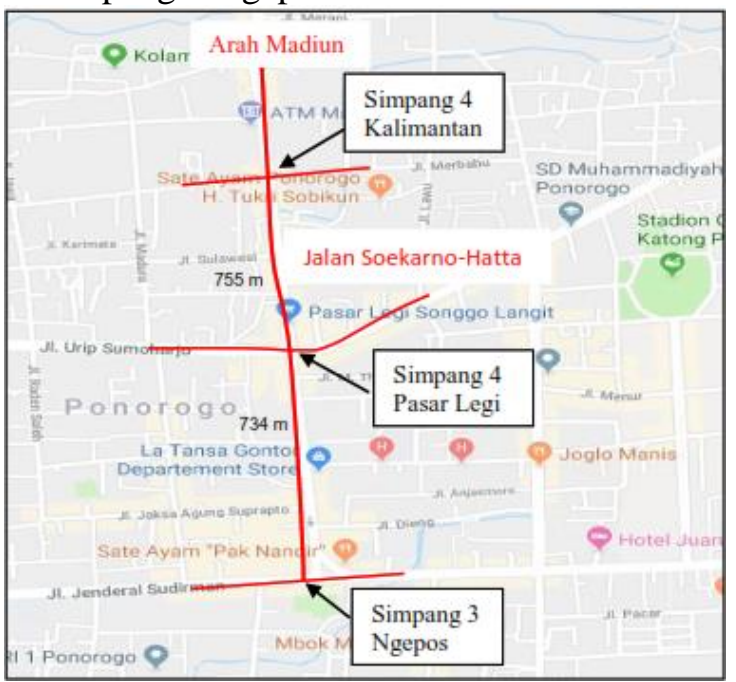

Gambar 1 Lokasi penelitian

Penelitian berupa pengambilan dan data primer. Pengambilan data Pelaksanaan survey yaitu survey inventarisasi simpang, survey volume lalu lintas, survey waktu siklus APILL eksisting, survey kecepatan ruas jalan dan waktu survey dilakukan pada weekday/hari kerja antara hari senin-kamis untuk mendapatkan data peak hour (jam sibuk).

\section{Analisis Data}

Analisis data menggunakan program Vissim11 yang mampu menganalisa data yang lebih akurat dan muncul visualisasinya dibanding program lainnya sehingga tampilannya mudah dipahami daripada beberapa program lainnya.

Analisis data primer menggunakan variabel tetap yang diambil dari hasil survey dan direkap kemudian di input masing-masing data selanjutnya dilakukan analisis data.

Tahapan analisis meliputi:

1. Penggambaran penampang simpang dan ruas jalan lokasi studi

2. Melakukan pengolahan dan analisis data pada masing - masing simpang

3. Pemasukan data pada program vissim -11

4. Melakukan running dan memunculkan visualisasi.

\section{HASIL DAN PEMBAHASAN}

\section{Kondisi Eksisting Persimpangan}

\section{Simpang 4 Kalimantan}

Simpang 4 Kalimantanmerupakan simpang yang terletak di Kelurahan Banyudono,
Kecamatan Ponorogo yang mempunyai 4 kaki simpang yaitu ruas Jalan Soekarno-Hatta 1, Jalan Soekarno-Hatta 2, Jalan Kalimantan dan Jalan Semeru. Simpang ini sudah menggunakan pengaturan simpang APILL sehingga sangat penting dalam penentuan waktu siklus APILL tiap simpang sehingga tidak menimbulkan antrian yang panjang dan pengguna banyak waktu terhambat pada simpang tersebut. Pengaturan waktu siklus APILL sangat dipengaruhi oleh beberapa indikator salah satunya adalah geometrik simpang sehingga kita lakukan survey inventarisasi untuk geometrik simpang 4 Kalimantan.

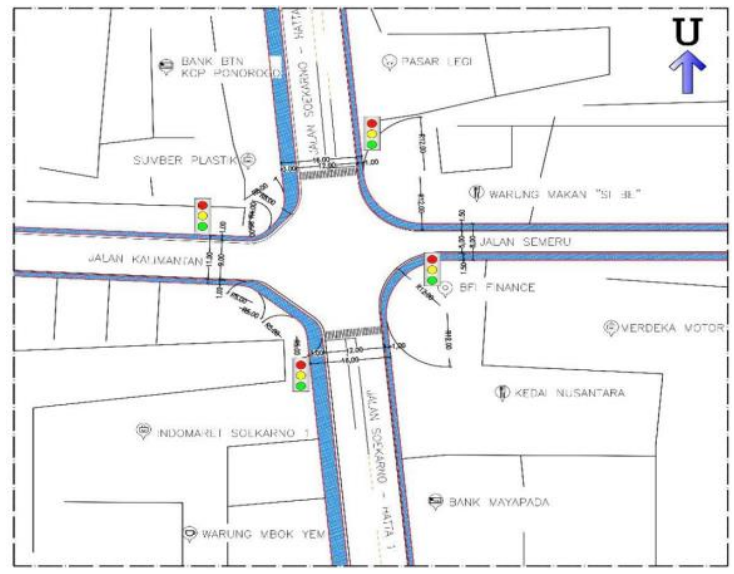

Gambar 2. Geometrik Simpang 4 Kalimantan

Berdasarkan gambar 2 geometrik simpang dapat kita simpulkan bahwa jalan SoekarnoHatta yang paling lebar ruas jalannya dibandingkan kaki simpang lainnya karena ruas jalan tersebut yang menghubungkan Kabupaten Ponorogo dengan Kota Madiun.

\section{Simpang 4 Pasar Legi}

Persimpangan Pasar Legi merupakan simpang yang terletak di Kelurahan Banyudono, Kecamatan Ponorogo yang mempunyai 4 kaki simpang yaitu ruas Jalan Soekarno-Hatta 2, Jalan Soekarno-Hatta 3, Jalan Urip Sumoharjo dan Jalan KH. Ahmad Dahlan, pada simpang ini sangat ramai karena terdapat pasar sehingga pergerakan kendaraan cukup padat pada simpang tersebut dan perlu adanya pengaturan APILL yang efektif agar adanya pengaturan APILL tidak membuat hambatan dan antrian tambah panjang pada masing-masing kaki simpangnya, gambar penampang melintang simpang seperti tampak pada gambar 3 .

\section{Simpang 3 Ngepos}


Persimpangan Ngepos merupakan simpang yang terletak di Kelurahan Kepatihan, Kecamatan Ponorogo yang mempunyai 3 kaki simpang yaitu ruas Jalan Soekarno-Hatta 3, Jalan Jend. Sudirman dan Jalan Gajah Mada, pada simpang ini sangat ramai karena terdapat kawasan pertokoan dan akses utama menuju alun-alun ponorogo dan pemda ponorogo sehingga pergerakan kendaraan cukup padat pada simpang tersebut dan perlu adanya pengaturan APILL yang efektif agar adanya pengaturan APILL tidak membuat hambatan dan antrian tambah panjang pada masingmasing, untuk lebih jelasnya seperti terlihat pada gambar 4 .

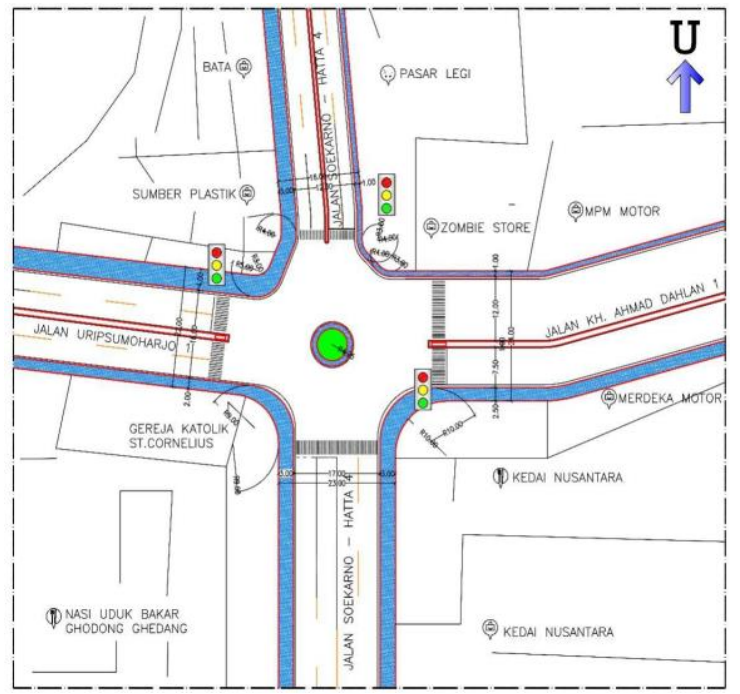

Gambar 3. Geometrik Simpang 4 Pasar Legi

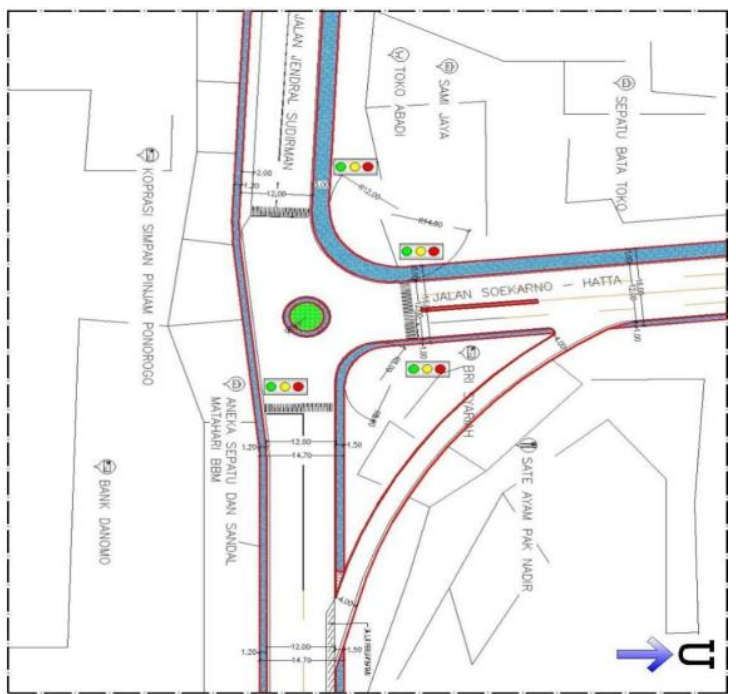

Gambar 4. Geometrik Simpang 3 Ngepos

\section{Kondisi Volume Lalu Lintas} Volume Lalu Lintas pada Simpang 4
Kalimantan
Data ini diambil dari tempat pengamatan yaitu pada simpang 4 Kalimantan seperti yang terlihat pada gambar 4.1. Rekapitulasi hasil perhitungan volume lalu lintas tersebut dinyatakan dalam satuan kend/jam, bertujuan adalah agar hasilnya lebih nyata. Data volume lalu lintas didapat dari pengamatan langsung dilokasi penelitian sehingga analisis yang akan dilakukan dapat diaplikasikan dilapangan sesuai dengan kondisi sebenarnya. Untuk menentukan jam sibuk kita lakukan terlebih dahulu survey traffic counting/survey pencacahan lalu lintas dari jam 05.00-21.00. Setelah mendapatkan jam sibuk ruas jalan Soekarno-Hatta maka kita lakukan survey lalu lintas pada simpang (CTMC) pada simpang 4 Kalimantan yang dilakukan selama 1 jam peak pagi tersibuk (06.00-07.00). Survei dilakukan dengan cara mencatat atau menghitung volume lalu lintas pada Simpang 4 Kalimantan, Simpang 4 Pasar Legi dan Simpang 3 Ngepos. Hasil perhitungan survei volume lalu lintas Simpang 4 Kalimantan ditunjukan dalam diagram arus lalu lintas pada Gambar 5.

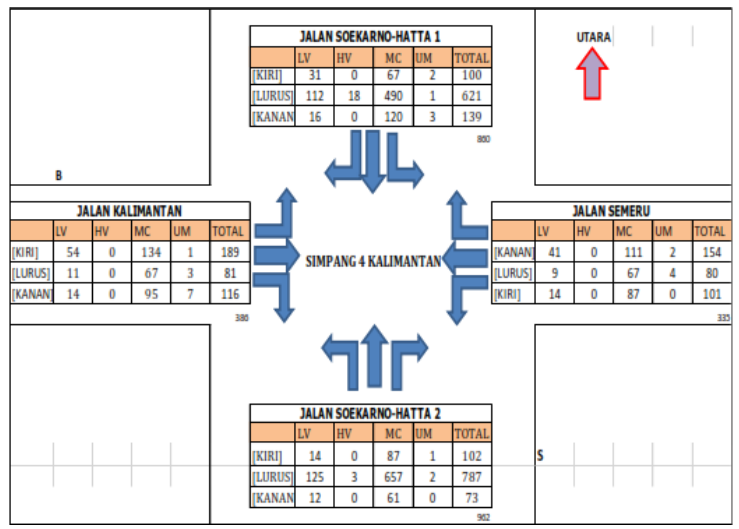

Gambar 5. Diagram arus lalu lintas simpang 4 Kalimantan

\section{Volume Lalu Lintas pada Simpang 4 Pasar Legi}

Untuk hasil survey simpang / CTMC pada simpang 4 Pasar Legi pada 1 jam tersibuk yaitu pukul (06.00-07.00) WIB dapat dilihat hasilnya pada Gambar 6.

\section{Volume Lalu Lintas pada Simpang 3 Ngepos}

Untuk hasil survey simpang / CTMC pada simpang $3 \mathrm{Ngepos}$ pada 1 jam tersibuk yaitu pukul (06.00-07.00) WIB pada tanggal 11 September 2019 dapat dilihat hasilnya pada Gambar 7. 


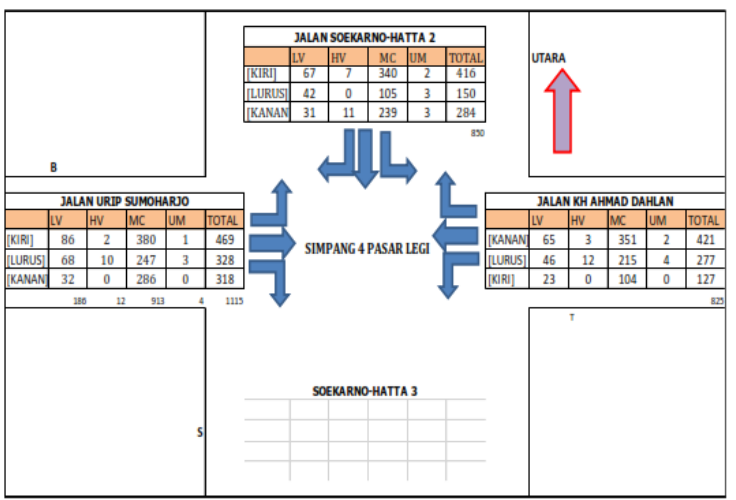

Gambar 6. Diagram arus lalu lintas simpang 4 Pasar Legi

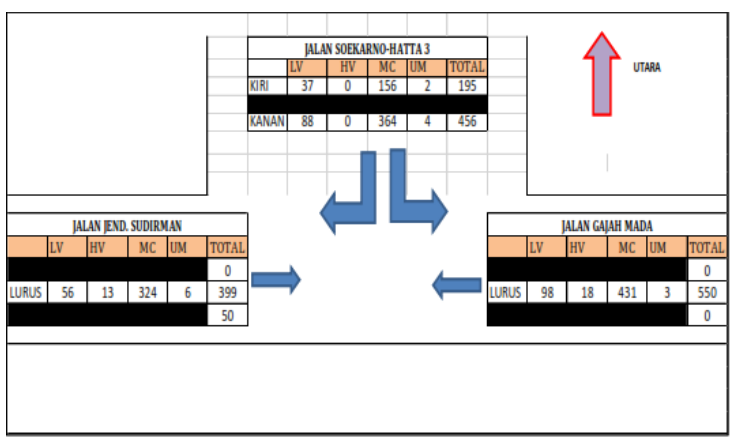

Gambar 7. Diagram arus lalu lintas simpang 3 Ngepos

\section{Kecepatan Kendaraan pada Ruas Jalan}

Dengan melakukan survey kecepatan pada ruas jalan dengan menggunakan speedgun dan MCO (moving Car Observer) maka dihasilkan kecepatan masing-masing kendaraan pada ruas jalan pada lokasi studi. Setelah dilakukan survey kecepatan pada Sembilan ruas jalan yang masuk dalam cakupan kajian, untuk lebih jelasnya dapat kita simpulkan kecepatan ratarata pada masing-masing ruas jalan sebagai berikut ; Jalan Soekarno-Hatta 1 adalah 50,24 $\mathrm{km} / \mathrm{jam}$, Jalan Soekarno-Hatta 2 adalah 48,56 $\mathrm{km} / \mathrm{jam}$, Jalan Soekarno-Hatta 3 adalah 45,32 $\mathrm{km} / \mathrm{jam}$, Jalan Semeru adalah 32,18 km/jam, Jalan Kalimantan adalah $36,46 \mathrm{~km} / \mathrm{jam}$, Jalan KH. Ahmad Dahlan adalah 43,80 km/jam, Jalan urip Suoharjo adalah $42,5 \mathrm{~km} / \mathrm{jam}$, Jalan Jend. Sudirman adalah $40,5 \mathrm{~km} / \mathrm{jam}$ dan Jalan Gajah Mada adalah 41,22 km/jam.

\section{Waktu Siklus APILL Kondisi Eksisting}

Waktu siklus pada masing - masing persimpangan pada kondisi eksisting digunakan untuk menganalisa tundaan dan antrian pada kondisi saat ini sehingga dapat diketahui permasalahan pada simpangnya dan dapat dicari solusi untuk mengatasinya untuk lebih jelasnya waktu siklus masing-masing simpang dapat dilihat sebagai berikut :

Tabel 1. Waktu Siklus APILL pada Simpang 4 Kalimantan (eksisting)

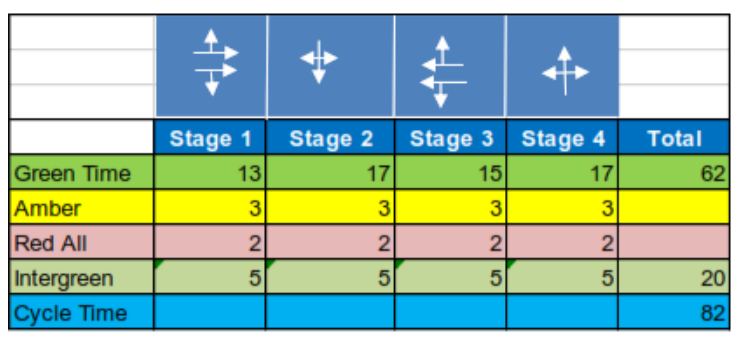

Dari tabel 1 maka dapat diketahui untuk total waktu siklus adalah 82 detik dengan pembagian waktu hijau masing-masing kaki simpang adalah 13 detik untuk dari arah barat (stage 1), 17 detik dari arah utara (stage 2), 15 detik dari arah timur (stage 3)dan 17 dari arah selatan (stage 4).

Tabel 2. Waktu Siklus APILL pada Simpang 4 Pasar Legi (eksisting)

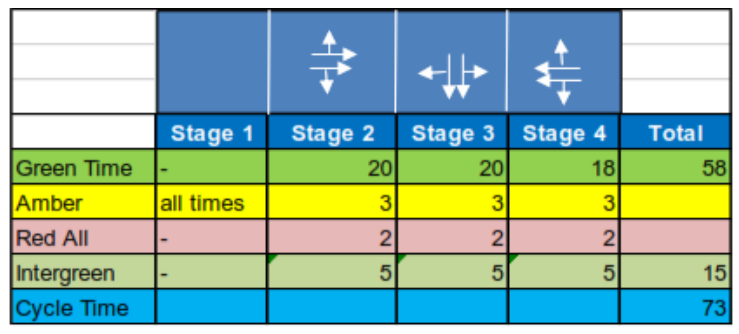

Dari tabel 2 maka dapat diketahui untuk total waktu siklus adalah 73 detik dengan stage 1 amber/kuning dan pembagian waktu hijau masing-masing kaki simpang adalah 20 detik untuk dari arah barat (stage 2), 20 detik dari arah utara (stage 3) dan 15 detik dari arah timur (stage 4).

Tabel 3. Waktu Siklus APILL pada Simpang 3 Ngepos (eksisting)

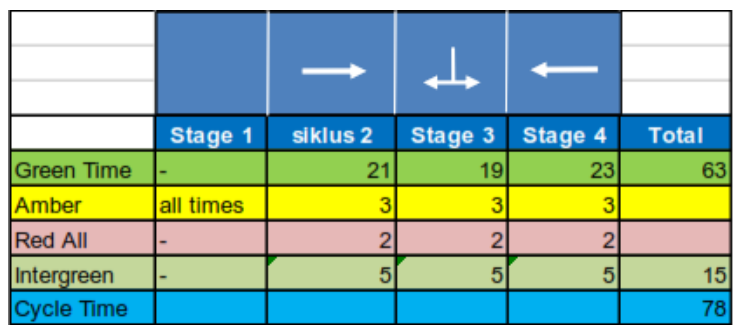

Dari tabel 3 maka dapat diketahui untuk total waktu siklus adalah 78 detik dengan stage 1 amber/kuning dan pembagian waktu hijau masing-masing kaki simpang adalah 21 detik untuk dari arah barat (stage 2), 19 detik dari arah utara (stage 3) dan 23 detik dari arah timur (stage 4). 
Berdasarkan tabbel 1, 2, dan 3 maka dapat diketahui waktu perjalanan yang dibutuhkan untuk melewati ketiga simpang tersebut adalah 190 detik (3 menit) karena masih banyak terdapat hambatan pada masing-masing simpang sehingga perlu dilakukan perubahan waktu siklus agar terkoordinasi sehingga waktu perjalanan dapat lebih cepat dan lancar dan hambatan yang ada dapat terkurangi.

\section{Proses Running pada Vissim-11 Kondisi Eksisting}

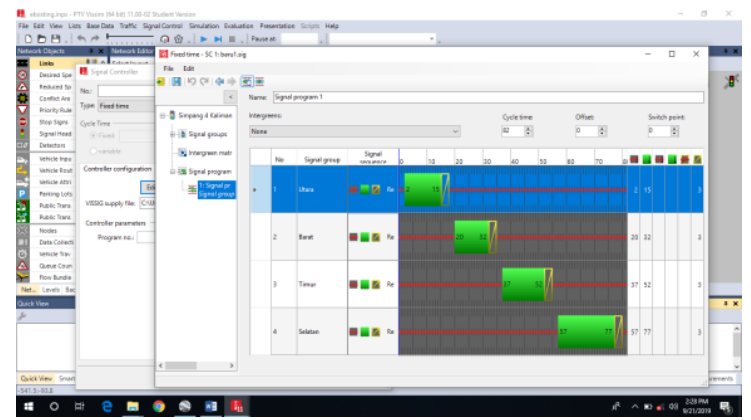

Gambar 8. Visualisasi input data pada aplikasi vissim-11
Setelah dilakukan survey dan rekap data kemudian langkah selanjutnya adalah memasukan data tersebut kedalam program vissim-11 dan kemudian langkah akhirnya adalah di running sehingga menghasilkan hasil-hasil analisa yang dilakukan oleh aplikasi vissim-11. Visualisasi proses pemasukan data dapat dilihat pada gambar 8 .

Dengan menggunakan aplikasi vissim-11 maka didapatkan beberapa data hasil analisa pada kondisi eksisting seperti tampak pada gambar 9. Dari hasil output vissim-11 pada gambar 9 untuk kondisi eksisting/saat ini panjang antrian dari arah utara Jalan Soekarno-Hatta 1 adalah 112 meter dan besarnya tundaanya adalah 75,74 detik sehingga masih perlu dilakukan optimalisasi terutama dari arah utara yaitu kendaraan dari arah Madiun yang akan menuju kawasan perkotaan Ponorogo. Selanjutnya dilakukan pula analisa untuk simpang lain yang ditinjau pada penelitian ini.

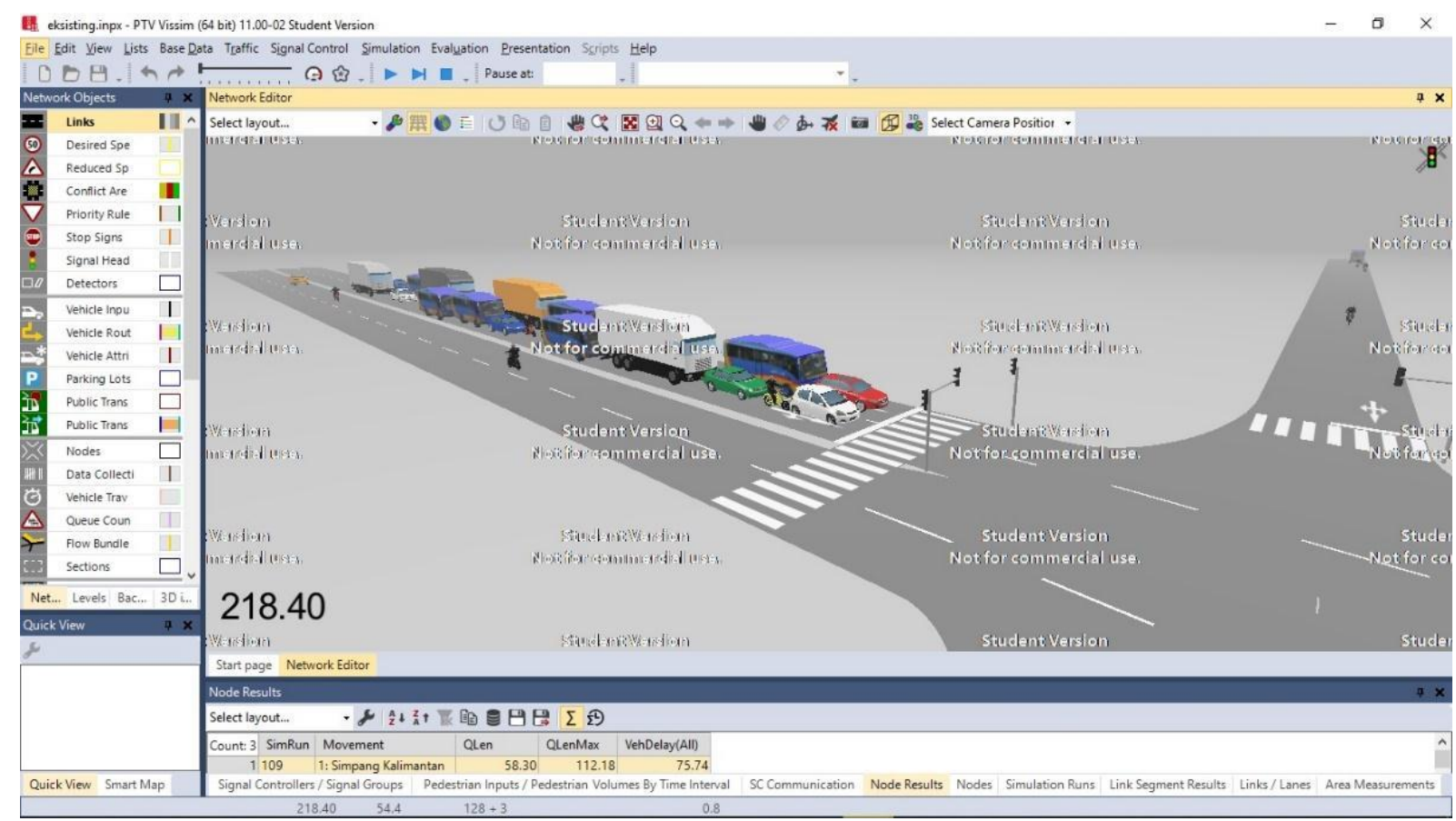

Gambar 9. Antrian Jalan Soekarno-Hatta 1 (dari utara) pada Simpang 4 kalimantan

\section{Proses Running pada Vissim-11 Rencana Usulan (Simpang Koordinasi)}

Setelah melakukan running pada kondisi eksisting maka diketahui panjang antrian, waktu tundaan, dan travel time (waktu perjalanan) masih cukup lama sehingga perlu adanya usulan perubahan siklus pada masingmasing simpang agar dari Simpang 4
Kalimantan sampai Simpang 3 Ngepos waktu siklusnya terkoordinasi usulan waktu siklus pada masing-masing simpang seperti tampak pada gambar 10, 11, dan 12.

Berdasarkan Gambar 10, 11, dan 12 maka dapat dilihat usulan perubahan waktu siklus masing-masing simpang agar terjadi koordinasi simpang pada persimpangan di ruas 
Jalan Soekarno-Hatta. Selain itu kecepatan rencana usulan didalam kota juga dipertimbangkan sebagai input data agar terjadi simpang koordinasi, karena berdasarkan Undang-Undang Nomor 22 Tahun 2009 bahwa batas maksimal kecepatan di dalam kota adalah $40 \mathrm{~km} / \mathrm{jam}$, tetapi untuk kecepatan rencana vissim direncanakan menjadi 35 $\mathrm{km} / \mathrm{jam}$. Sebagai input aplikasi ini maka kecepatan rencana untuk terjadinya simpang terkoordinasi adalah kecepatan rata-ratanya 35 $\mathrm{km} / \mathrm{jam}$.

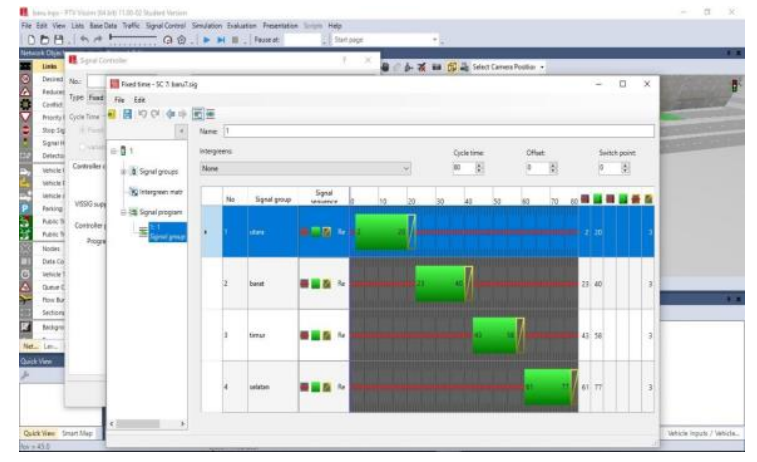

Gambar 10. Waktu Siklus Usulan pada simpang 4 Kalimantan

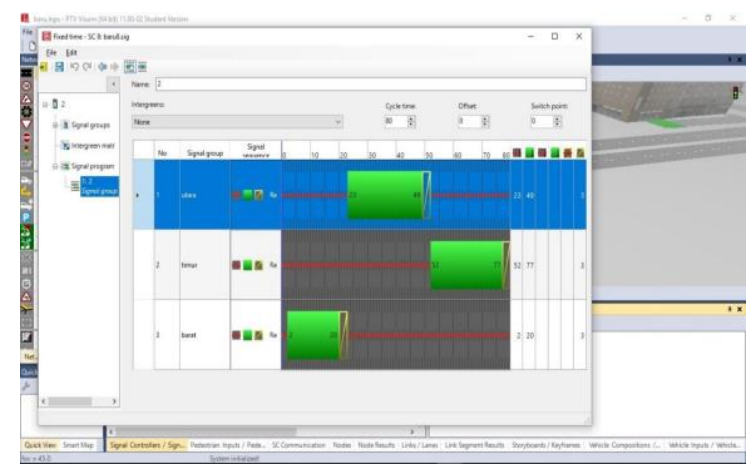

Gambar 11. Waktu Siklus Usulan pada simpang 4 Pasar Legi

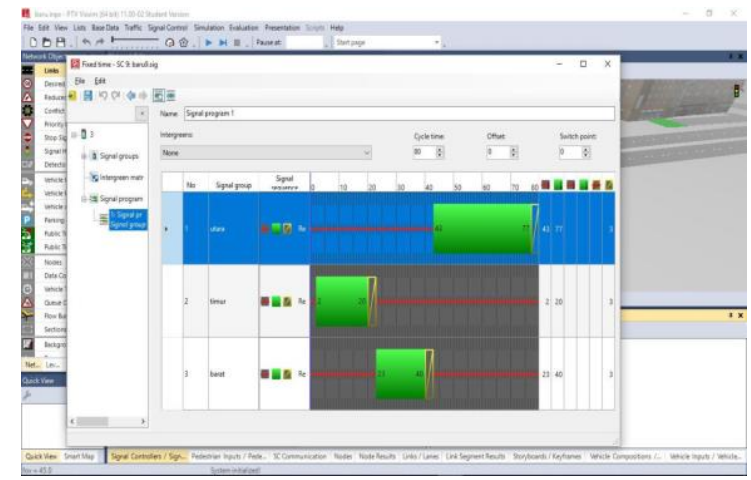

Gambar 12. Waktu Siklus Usulan pada simpang 4 Ngepos

Berdasarkan hasil running vissim-11 rencana usulan seperti tampak pada gambar 13 maka disimpulkan untuk panjang antrian Jalan Soekarno-Hatta 1 pada simpang 4 kalimantan adalah 7 meter dan waktu tundaannya adalah 0,03 detik sehingga sudah membaik dibandingkan sebelum dilakukan perubahan waktu siklus. Kemudian dilakukan juga running vissim-11 rencana usulan untuk simpang lain yang ditinjau. Hasil running rencana pada simpang 4 Pasar Legi menunjukan hasilnya sudah membaik dibandingkan sebelum dilakukan perubahan waktu siklus diamana Jalan Soekarno-Hatta 2 panjang antrian 30 meter dan 0,015 detik. Kinerja Jalan Soekarno-Hatta 1 pada simpang 3 Ngepos yang setelah dilakukan perubahan waktu siklus dan kecepatan rencana 40 $\mathrm{km} / \mathrm{jam}$, panjang antriannya menjadi 17 meter dan waktu tundaanya menjadi 0,00 detik. Dari ketiga hasil pada persimpangan yang diuji makas kinerja masing-masing persimpangan sudah membaik dibandingkan sebelumnya dan untuk lebih jelasnya perbandingan masingmasing kinerja Jalan Soekarno-Hatta dapat dilihat pada tabel 4 .

Tabel 4. Perbandingan Kinerja Ruas Jalan Soekarno-Hatta Kondisi Eksistingdan Rencana Usulan

\begin{tabular}{|c|c|c|c|c|c|c|c|c|c|c|}
\hline \multirow{2}{*}{ No } & \multirow{2}{*}{ NAMA SIMPANG } & \multirow{2}{*}{ NaMaialaN } & $\begin{array}{l}\text { PANIANG } \\
\text { ANTRILAN }\end{array}$ & \begin{tabular}{|l} 
WAKTV \\
TUNDAAN
\end{tabular} & $\begin{array}{l}\text { RECEPATAN } \\
\text { RATA-RATA }\end{array}$ & \begin{tabular}{|c|} 
WAKTT \\
PERALANAN
\end{tabular} & $\begin{array}{l}\text { PANIANG } \\
\text { aNTRAN }\end{array}$ & $\begin{array}{c}\text { WAKTU } \\
\text { TUNDALA }\end{array}$ & $\begin{array}{l}\text { RECEPATAN } \\
\text { RATA-RATA }\end{array}$ & \begin{tabular}{|l} 
WAKTU \\
PERIALANAN
\end{tabular} \\
\hline & & & \multicolumn{4}{|c|}{ KONDISI EXSIITTING / SAATINI } & \multicolumn{4}{|c|}{ KondSI Revcana usuLAN } \\
\hline 1 & Simpang 4 Kalimantan & Ialan Soekamo-Hatta 1 & 112 meter & 75,74 detik & $50,24 \mathrm{~km} / \mathrm{jam}$ & \multirow{3}{*}{ 190detik } & 22,3 meter & 0,03 detik & $35 \mathrm{~km} / \mathrm{jm}$ & \multirow{3}{*}{65 detik } \\
\hline 2 & Simpang 4 Parar legi & Ialan Soekamo-Hatta 2 & 90meter & 23,26 detik & $48,56 \mathrm{~km} / \mathrm{jam}$ & & 30,85 meter & 0,15 detik & $35 \mathrm{~km} / \mathrm{jmm}$ & \\
\hline 3 & Simpang 3 Ngepos & Ialan Sceklamo-Hatta 3 & 72 meter & 29,99 detik & $45,32 \mathrm{~km} / \mathrm{jam}$ & & 17,80 meter & 0,00 detik & $35 \mathrm{~km} / \mathrm{jmm}$ & \\
\hline
\end{tabular}




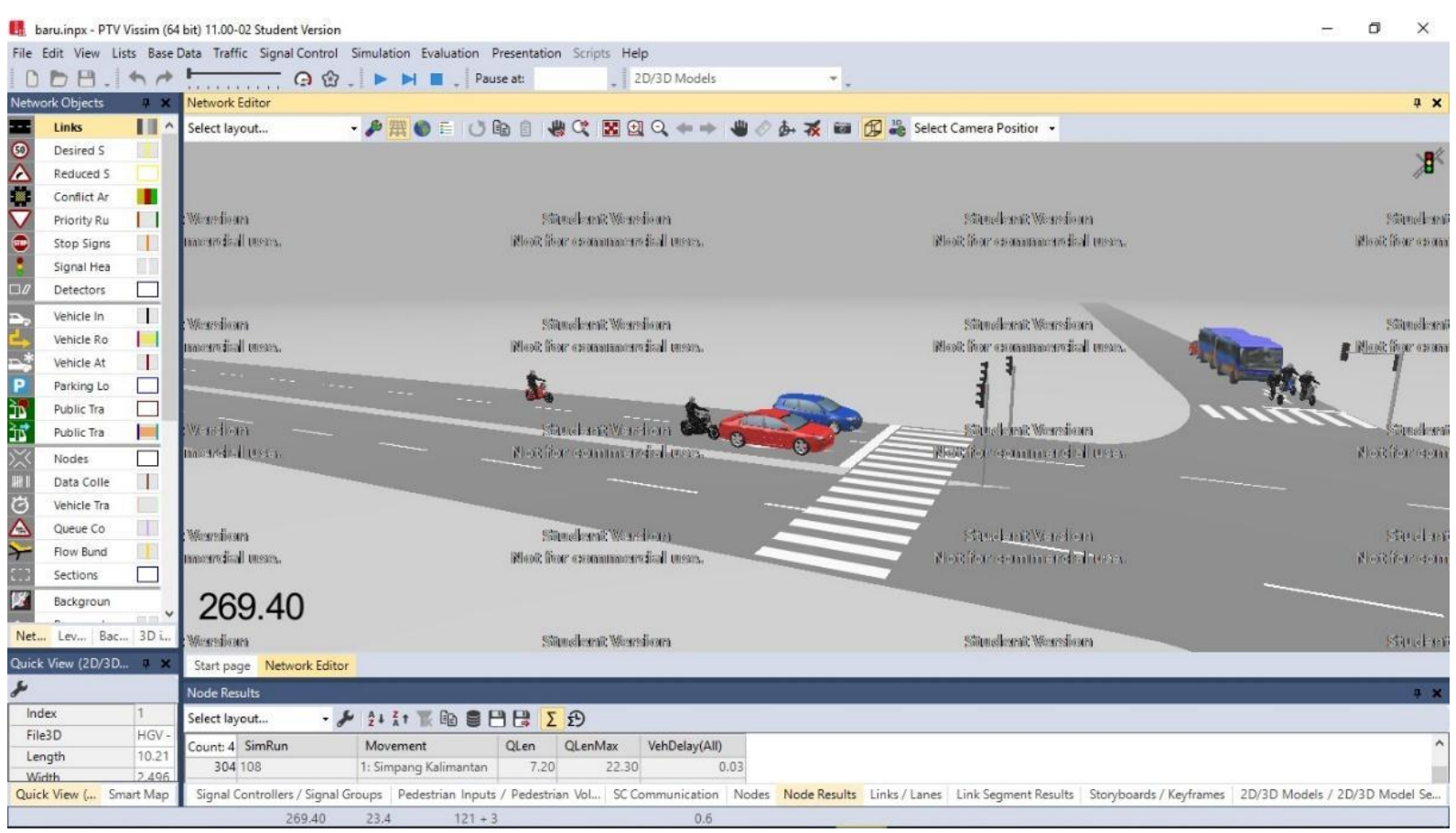

Gambar 13. Panjang Antrian dan Waktu Tundaan Rencana Pada Simpang 4 Kalimantan

Dari tabel 4 didapatkan perbedaan kinerja pada ruas Jalan Soekarno-Hatta sebelum dilakukan rekayasa lalu lintas dengan perubahan waktu siklus pada APILL dan usulan perencanaan kecepatan kendaraan $35 \mathrm{~km} / \mathrm{jam}$ sehingga untuk kendaraan dari arah Madiun menuju Kabupaten Ponorogo arus lalu lintasnya tidak terhambat dan mempercepat waktu perjalanan untuk semua kendaraan.

\section{SIMPULAN}

Menurut hasil penelitian dan analisa pada kondisi eksisting kinerja ruas Jalan SoekarnoHatta 1 adalah panjang antriannya 112 meter dan waktu tundaannya 75,74 detik, kemudian panjang antrian pada ruas Jalan SoekarnoHatta 2 adalah 90 meter dan 23,26 detik,waktu tundaannya dan yang terakhir Jalan SoekarnoHatta 3 adalah panjang antriannya 72 meter dan waktu tundaannya 29,99 detik.

Pada kondisi eksisting kecepatan ruas Jalan Soekarno-Hatta 1 masih diatas $45 \mathrm{~km} / \mathrm{jam}$ dan waktu siklus ketiga simpang tersebut tidak terkoordinasi yaitu simpang 4 Kalimantan, Simpang 4 Pasar legi dan Simpang 3 Ngepos.

Setelah dilakukan perubahan waktu siklus dan kecepatan rencana menjadi $40 \mathrm{~km} / \mathrm{jam}$ maka terjadinya kordinasi antara ketiga simpang tersebut sehingga kinerja ruas Jalan Soekarno-
Hatta 1 menjadi panjang antrian $=22,3$ meter, waktu tundaan $=0,03$ detik kemudian ruas Jalan SoekarnoHatta 2 menjadi panjang antrian $=30,85$ dan waktu tundaanya 0,15 detik dan yang terakhir Jalan Soekarno-Hatta 3 dengan panjang antrian $=17,80$ dan tundaannya 0,00 detik.

Kecepatan rencana jalan Soekarno-Hatta untuk terjadinya koordinasi simpang adalah 35 $\mathrm{km} / \mathrm{jam}$ dibawah batas maksimal kecepatan dikawasan perkotaan dan travel time atau waktu perjalanan yang sebelumnya 190 detik (3 menit) menjadi 65 detik.kesimpulan dapat juga dituliskan hal-hal yang akan dilakukan terkait dengan gagasan selanjutnya dari penelitian tersebut. Kesimpulan ditulis dalam paragraf utuh, bukan poin per poin.

Untuk memperlancar arus lalu lintas dari wilayah Madiun menuju perkotaan Ponorogo pihak berwenang yang berhak menentukan kebijakan mengatur ulang siklus APILL pada ketiga simpang tersebut di atas dan memberikan rambu batas kecepatan pada kawasan perkotaan $40 \mathrm{~km} / \mathrm{jam}$ dengan harapan kecepatan pengendara di ruas Jalan SoekarnoHatta rata-ratanya 35 km/jam.

Diharapkan pemerintah menentukan kebijakan selanjutnya yaitu penggunaan system ATCS (Area Traffic Control System) pada semua APILL di Kabupaten Ponorogo. 


\section{UCAPAN TERIMAKASIH}

Ucapan terima kasih ditujukan kepada Dinas Perhubungan Kabupaten Ponorogo yang telah membantu pelaksanaan penelitian ini.

\section{DAFTAR PUSTAKA}

AG, P., 2017. PTV VISSIM. https://en.wikipedia.org/wiki/PTV_VISSI M.

Arifin, M., 2019. Analisis Kemacetan Lalu Lintas di Persimpangan Jl. Kapten Mulyadi. Modul. Media Komun. Dunia Ilmu Sipil 1, 16-24.

Firman, B., 2016. Rancang Bangun Sistem Kendali Alat Pemberi Isyarat Lalu Lintas ( APILL ) Nirkabel Berbasis Wireless Sensor Network ( WSN ) M ...., in: Rancang Bangun Sistem Kendali Alat Pemberi Isyarat Lalu Lintas (APILL) Nirkabel Berbasis Wireless Sensor Network (WSN) Menggunakan ZigBee $2.4 \mathrm{GHz}$.

Ikhwan, M., Legowo, S.J., MHM, A., 2014. Analisa dan Koordinasi Sinyal antara Simpang Sumber dan Simpang Pom Bensin Manahan ( Studi Kasus Simpang Ruas Jalan Jenderal Ahmad Yani Surakarta ). Matriks Tek. Sipil 2, 351359.

Khafidz, L., Sumarsono, A., Mhm, A., 2016. Hubungan Tundaan dan Panjang Antrian Terhadap Konsumsi Bahan Bakar
Minyak pada Lajur Pendekat Simpang (Studi Kasus pada Jalan Arteri Kota Surakarta). Matriks Tek. Sipil 774-780.

Nurdjanah, N., 2019. Biaya BBM Akibat Kemacetan di Persimpangan Wilayah Jabodetabek (Fuel Costs Because of Congestion In The Intersection of Jabodetabek). J. Penelit. Transp. Darat. https://doi.org/10.25104/jptd.v15i4.1201

Paramarto, N., Hartono, P., Ismiyati, Setiadji, B.H., 2014. Analisis Kinerja Simpang Bersinyal Dengan Menggunakan Program Synchro (Studi Kasus pada Simpang Jl. Majapahit - Jl. Fatmawati dan Jl. Majapahit - Jl. Soekarno Hatta, Semarang). J. Karya Tek. Sipil 3, 485497.

Sari, R.R., 2017. Pengaruh Pemberlakuan Rekayasa Lalulintas Terhadap Derajat Kejenuhan Pada Simpang Jalan Pajajaran dan Jalan Pasirkaliki. Potensi J. Sipil Politek.

https://doi.org/10.35313/potensi.v19i2.89 9

Tamin, O.Z., 2008. Perencanaan, Permodelan, \& Rekayasa Transportasi: Teori, Contoh Soal, dan Aplikasi, ITB.

Zega, M., Surbakti, M.S., 2013. Analisa Koordinasi Sinyal Antar Simpang (Studi kasus : Jl. Jamin Ginting - Jl. Pattimura Jl. Mongonsidi). J. Tek. Sipil USU 2. 